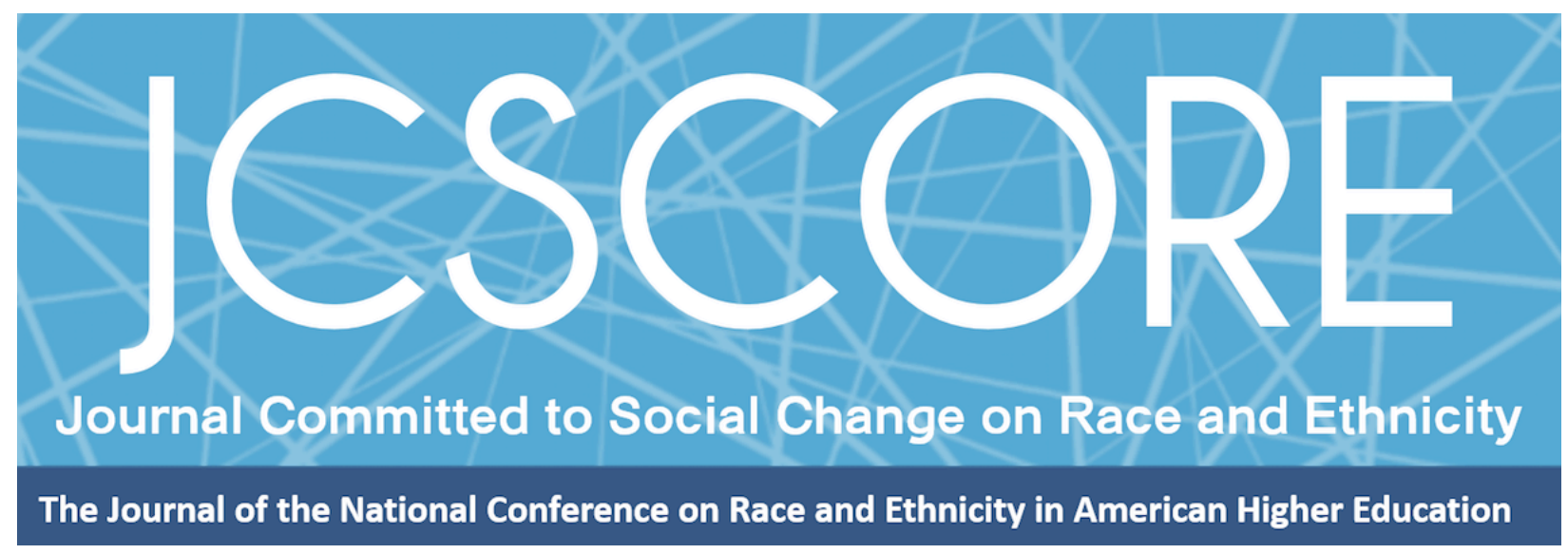

\title{
DIVERSITY COMPETENCE WITHIN FACULTY-LED STUDY ABROAD PROGRAMS
}

Jakia Marie

University of Louisville

Kimberly N. Sanders

University of Louisville

Journal Committed to Social Change on Race and Ethnicity

Volume 4, Issue 2 | 2018

Copyright @ 2018 Board of Regents of The University of Oklahoma on behalf of the Southwest Center for Human Relations Studies.

Permission of the Publisher is required for resale or distribution and for all derivative works, including compilations and translations. Quoting small sections of text is allowed as long as there is appropriate attribution. 


\title{
DIVERSITY COMPETENCE WITHIN FACULTY-LED STUDY ABROAD PROGRAMS
}

\author{
Jakia Marie \\ University of Louisville \\ Kimberly N. Sanders \\ University of Louisville
}

\begin{abstract}
Previous studies have noted the positive role studying abroad has played in the lives of students; however, there are clear disparities in the structure of facultyled study abroad programs that limit students' ability to fully maximize the usefulness of these experiences. Focusing on the role of faculty leaders in study abroad programs, this paper critically examines extant literature related to student experiences studying abroad. Through our examination of existing research, we conclude that it is essential for faculty to be more competent in relation to diversity and be aware of their positionality and the intersecting identities of their students before departing to the host country. We argue this prerequisite creates a more equitable and optimal learning experience for students.
\end{abstract}

International education and studying abroad have been on a steady rise in the United States. According to the Institute of International Education (IIE, 2017), 325,339

U.S. students studied abroad for academic credit in the 2015-2016 academic year, which was an increase of $3.8 \%$ from the previous year. As more U.S. students choose to take part in these programs, the diversity of the study abroad participants has also increased with more students holding marginalized racial identities choosing to study abroad (see Table 1). These increases have resulted in more diversified programs than institutions have previously encountered.

As faculty-led study abroad programs become more racially and ethnically diverse, there is a growing need for faculty to develop diversity competence as they spearhead these initiatives. Diversity competency is crucial as it aids them in creating learning environments that encourage students to engage in self-reflection and personal 
identity development. Faculty with a higher diversity competence have better capacities to facilitate intragroup dialogue and conflict resolution in an effective way that does not isolate minoritized students. We argue that faculty with a higher diversity competence will enhance the student experience by creating a more positive experience for all students and a deeper level of engagement for all involved.

\begin{tabular}{|c|c|c|c|}
\hline \multicolumn{4}{|c|}{$\begin{array}{l}\text { Table } 1 \\
\text { Race/Ethnicity of U.S. Students Abroad }\end{array}$} \\
\hline Race/Ethnicity & $2004 / 05$ & $2009 / 10$ & $2015 / 16$ \\
\hline$\overline{\text { White }}$ & $\overline{83.0}$ & $\overline{78.7}$ & $\overline{71.6}$ \\
\hline Hispanic or Latino(a) & 5.6 & 6.4 & 9.7 \\
\hline Asian or Pacific Islander & 6.3 & 7.9 & 8.4 \\
\hline Black or African American & 3.5 & 4.7 & 5.9 \\
\hline Multiracial & 1.2 & 1.9 & 3.9 \\
\hline American Indian or Alaska Native & 0.4 & 0.5 & 0.5 \\
\hline TOTAL U.S. STUDENTS ABROAD & 205,983 & 270,604 & 325,339 \\
\hline
\end{tabular}

Adapted from “Open Doors Fast Facts, 2017," by IIE, 2017, New York, NY.

Though there is a growing number of Students of Color who pursue international travel as a part of their post-secondary educational experience, the demographics of study abroad participants reflect the historical underrepresentation of racial and ethnic minorities in higher education as a whole. In fact, the majority of students who choose to study abroad are traditional age white females, with the female to male ratio being two to one (Twombly, Salisbury, Tumanut, \& Klute, 2012). The 2017 Open Doors report shows that for the $2015-2016$ academic year, $66.5 \%$ of American students who studied abroad were female and $71.6 \%$ of all students who studied abroad were white (IIE, 2017).

While previous research explores the personal experiences of students in relation to the positive benefits of international travel, there is little to no research that 
specifically examines the intragroup relationships between study abroad participants and faculty's role in cultivating a learning environment where students learn about themselves and about the host countries. Faculty are vital to many study abroad programs, and research concerning them and their interactions with students should be further explored. The purpose of this paper is to contribute to that exploration.

\section{Diversity Competency}

Diversity competency is "a process of learning that leads to an ability to effectively respond to the challenges and opportunities posed by the presence of socialcultural diversity in a defined social system" (Cox \& Beale, 1997, p. 2). It is important to note that the diversity in diversity competency is not limited to cultural differences but also includes social identities (Chun \& Evans, 2016). Chun and Evans (2016) noted a unique importance in the term competency arguing, "The notion of educational competencies move away from the realm of knowledge for its own sake to the application of knowledge through specific competencies" (p. 34). Competency-based educational models are focused on outcomes where, through a learner-centered approach, skillsets are developed (Chun \& Evans, 2016; Frank et al., 2010). Using Bierema's (2010) understanding of diversity education, we believe study abroad programs to be a type of diversity education. Faculty in their role as study abroad leaders must understand the cultures and cultural differences of the host country, while also recognizing how the identities of the student participants shape their interactions with and perspectives of the host country as well as with other group members. Further, they must possess the ability to facilitate meaningful dialogue within these diverse groups. 
In order to better understand the complexities of diversity competency as it relates to international travel for U.S. students, we have parsed the literature into three sections: study abroad initiatives broadly speaking, faculty-led study abroad programs, and finally the experiences of study abroad participants. We then provide literaturebased analyses for faculty prior to the trip, during the trip, and after returning home because education abroad consists of these three distinct phases (Jackson, 2015; Sachau, Brasher, \& Fee, 2010). This critical review of existing literature demonstrates why or why not students participate in study abroad programs, the influence of faculty on these trips, and intragroup cultural dynamics.

\section{Studying Abroad}

Students choose to study abroad for a number of reasons, and these motivators may be due to the types of programs offered. For this paper, we must acknowledge that our concern is with what Engle and Engle (2003) considered culture-based international education, which is primarily oriented in language and culture. This is to say that this paper analyzes and provides suggestions for programs that are focused on cultural immersion and/or language proficiency.

The desire for cultural awareness has increased among college students (Anderson, Lawton, Rexeisen, \& Hubbard, 2006; Anderson, Lorenz, \& White, 2016), and international travel has been used as a means to meet the demand. International education is a tool to develop global citizens as studying abroad can positively impact students' cultural diversity, self-awareness, and world affairs perspectives (Rhodes, Biscarra, Loberg, \& Roller, 2012). These culturally diverse worldviews are long-term and 
Journal Committed to Social Change on Race and Ethnicity | 2018

can influence career choices and desires to continue learning about other cultures (Rhodes et al., 2012).

Though student interest in studying abroad has increased in recent years, there are a number of constraints facing these students that may prevent them from traveling abroad. Analyzing data from the Wabash National Study of Liberal Arts, Salisbury, Paulsen, and Pascarella (2011) examined the differences between races in the factors that influenced students' intent on studying abroad. There was a correlation with ACT scores and intent to study abroad, but this correlation had different effects for White and African American students. African American students were more likely to have an intent on studying abroad as their ACT scores increased, while higher ACT scores did not seem to have an influence on White students' intent to study abroad. White students who received federal grants were less likely to intend on studying abroad, while Latino students who received federal grants were more likely to study abroad.

In a similar fashion, Brux and Fry (2010) hosted focus groups and administered surveys with the Asian American Student Association, Black Student Union, and Latino Student Organization at the University of Wisconsin-River Falls to gain a deeper understanding of the constraints students face when deciding to participate in study abroad programs. Students from the Latino Student Organization expressed they had reservations concerning language barriers, financial constraints, schedules, and food when considering studying abroad. While these concerns were present, some discussed how they felt more comfortable and welcome in other countries than they did in the United States. African American students conveyed how they, along with their family members, had concerns regarding racism abroad. Participants also expressed 
their concerns about being the other or minority in a study abroad group and the host country. Additionally, the authors found that African American students were more interested in African topics and Asian American students were more interested in Asian topics, demonstrating a clear connection between ancestry and interest in study abroad region (Brux \& Fry, 2010).

While Students of Color have an interest in studying abroad, many have constraints that are different from their White peers. What makes these constraints unique is that they are rooted in lived experiences_lived experiences, including racism, to which most White Americans have never been subjected. We contend for faculty to engage with their student participants on a deeper level and encourage a healthy intragroup relationship with student participants, they must understand students' intent, perceptions, and constraints are likely to differ based on identity.

\section{Faculty-led Study Abroad Programs}

Short-term study abroad programs have proven to be a popular option in study abroad participation because not all students have the time or money to spend a semester or more abroad (Dwyer, 2004; Hovde, 2002; Sachau et al., 2010). According to the Institute of International Education 2017 Open Doors report, 38\% of students who studied abroad did so in the summer and $17.4 \%$ of students who studied abroad did so in eight weeks or less during the academic year. Short-term programs are the most popular choice for U.S. students, and faculty-led short-term programs are a popular option for many students (Fischer, 2009). Institutions of higher education have been tasked with promoting international opportunities "that transport participants well beyond 
the role of a tourist, educational consumer, or isolated and unengaged American abroad" (Mohajeri Norris \& Gillespie, 2008, p. 383).

When compared to longer programs, short-term faculty-led programs often provide more structure, guidance (Gutierez, Averbach, \& Bhandari, 2009, as cited in Mullens \& Cuper, 2012), and offer a greater sense of security for students and inexperienced travelers. Short-term faculty-led programs are also more accessible for students (Mullens \& Cuper, 2012). During short-term programs, faculty have greater control over student activities compared to longer programs. They have the ability to be much more purposeful and can facilitate focused learning (Mapp, 2012). Faculty can cater the travel activities to closely align with the content of students' coursework back home (Donnelly-Smith, 2009) and provide students with applied experiences that aid in learning (Gaia, 2014). Students participating in short-term programs are more likely to travel, find lodging, and explore the host country with a group of other students and faculty as opposed to doing all of this alone (Dwyer, 2004).

In these shorter trips, faculty can be much more hands-on and involved in the student experience abroad. Longer trips create opportunities to be more independent, but students report having less contact with the culture of the host country and are less likely to interact with local residents (Donnelly-Smith, 2009). Further, the presence of a faculty member traveling with participants leads students and their families to feel that these experiences are safer than long-term ones (Gaia, 2014). Contributing to the uniqueness of faculty-led programs is the fact that each faculty-led program is different based on the professor, location, and course offerings. 
Journal Committed to Social Change on Race and Ethnicity | 2018

Students report that faculty relationships (Lu, Reddick, Dean, \& Pecero, 2015) and program structure (Herbst, 2011) influence their decisions to study abroad. In their examination of Black students who studied abroad, in China, Lu et al. (2015) discovered that the faculty member who led the trip was a primary reason students chose to participate in the specific program. All 24 of the Black students were current or former students of the faculty member who led the program and all participants agreed that without the faculty member's influence, they might not have decided to study abroad. Participants noted their positive relationship with the faculty member and the faculty member's investment in their study abroad experience were important factors when deciding to study abroad.

Program offering is also an important factor impacting a student's decision to study abroad. Data from the IIE (2017) note that only $7.4 \%$ of U.S. students who studied abroad during the 2015-2016 academic year were majoring in a foreign language and international studies. Herbst (2011) explained the fear of language barriers can be a concern for many students, and institutional promotions for his study abroad program were sure to stress the fact that there were no language requirements for his program. The structure of programs is important to students when considering the credits students earn and the language requirements.

Faculty-led programs are distinct from other types of study abroad initiatives not only because of the presence of faculty, but also because of their course structure, influence, and relationships with students. The structure of faculty-led programs is important for student development. Anderson et al. (2016) maintain that short-term, instructor-led study abroad programs have the ability to positively influence intercultural 
development. Faculty-led programs also have the potential to provide programs that encourage intentional, critical reflection of host country engagement (Engle \& Engle, 2003). The importance of faculty is not always known to students but clearly becomes more relevant as they decided to participate in studying abroad. Although students have acknowledged positive relationships with their faculty, research shows a disconnect between student intragroup relationships.

\section{Experiences of Study Abroad Participants}

Individuals interpret the same international experiences differently, but clear themes emerge when analyzing experiences based on race and ethnicity. Specifically, during our review, we found participants' perceptions of their international experiences based on location can be different when comparing students who are racial or ethnic minorities in the country or majority in the country. While current research insists undeniable benefits as a direct result of studying abroad, few studies explore the counternarratives of students who express negative experiences abroad. These narratives are necessary to better understand the experiences of all students. While individuals hold various identities, the primary focus on counternarratives in the literature is often related to race and ethnicity (e.g., Chang, 2017; Lu et al., 2015; Shallenberger, 2015).

Chang (2017) explored the relationship between identity and studying abroad with four Latina students studying abroad in Guatemala. One theme found to be consistent was the difference in cultural dissonance between participants. The Latina participants all identified moments when they felt cultural tensions among their White peer participants. What makes this theme most important is that the White students 
were apparently unaware of this cultural dissonance that occurred in everyday interactions. One way this cultural dissonance was exemplified was with the clear, distinct ideologies of the participants' interaction with the host country and citizens of Guatemala. The Latina participants felt the White students treated the native residents more as objects and not human beings. Overall, the Latina participants reported that the cultural difference with their White peers was a prominent factor that affected their overall study abroad experience. The identities the Latina students held gave them a different perspective while in Guatemala which was unique compared to their White counterparts.

In his work on reflection and building stronger study abroad programs, Shallenberger (2015) revealed that an African American student expressed that he had an uncomfortable situation that he attributed to racism, but Shallenberger, the faculty leader, suggested that it may have been a cultural difference and not racism. Shallenberger (2015) acknowledged that his intervention halted the student's processing and the student no longer felt comfortable sharing with Shallenberger. Further, he notes that missteps such as this are fairly common among international educators (Shallenberger, 2015).

While being a racial minority in the host country may create an environment that fosters negative interactions or perceptions, identifying as being amongst the racial majority can lead to positive experiences for students who identify as members of minoritized racial and ethnic groups while at home. Mitchell and Maloff (2016) explored how the U.S. construct of race influenced the study abroad experience for graduate students in Jamaica. Of those who participated in the study, each of the African 
American students felt more comfortable being a part of the racial majority in a country while the White students were more likely to become more aware of their racial position in Jamaica and the United States. The students' racial identities affected the way they interacted with the country and how they reflected on their experience in comparison to their experiences in the United States.

In their study of Black students studying abroad in China, Lu et al. (2015) revealed being the ethnic minority in China was not a prominent concern for the students because they were accustomed to being the racial minority in the United States and being marginalized at their predominantly White institution. This is important to note because it highlights how lived experiences in the United States influence perceptions of experiences abroad as well as how race and ethnicity influence these experiences and perceptions. The Black students in this study also explained that they were treated differently while in China as compared to the White and Latino students. The Black students were given more attention by the Chinese citizens, and the most common reason disclosed was because of their skin color.

While each individual will interpret their experiences differently, the literature highlights themes for students who study abroad that show similarities of perception based on race and ethnicity. The acknowledgement of different cultural interpretations and experiences is important for faculty to note when leading study abroad programs (Shallenberger, 2015), in order to be able to address these experiences before they occur, to address them during the trip, and to improve the experiences of the students while in the host country and with their fellow study abroad participants. We contend it is 
Journal Committed to Social Change on Race and Ethnicity | 2018

this understanding that serves as the foundation for the need of more faculty with a stronger sense of diversity competency involved in study abroad programs.

\section{Diversity Competency and Study Abroad: An Analysis}

Much of the literature surrounding the topic of students studying abroad discusses the dissonance or disorientation that students experience which is referred to as culture shock (Trilokekar \& Kukar, 2011). These feelings of discomfort and being an outsider are recognized as some of the causes of the personal growth students face (Trilokekar \& Kukar, 2011). Smith, Jennings, and Lakhan (2014) assert that students need to engage in an intentional self-exploration and reflection on their personal and cultural backgrounds to recognize how their upbringing has shaped the way they see and interpret the world.

While much of the literature focuses on how students can reflect on their experiences in comparison to their cultural upbringings as one step to becoming more culturally competent, faculty must also develop diversity competencies and reflect on their biases as they lead study abroad programs (Shallenberger, 2015). Few studies have conducted pretests-posttests to quantify the changes that occur with students while abroad (e.g., see Anderson et al., 2006). Further, there is little to no research specifically examining the role faculty play in the development of student multicultural competencies using pretest-posttest methodologies. While the literature is limited, there are scholars who have captured the experiences of students based on their perspective using phenomenological approaches (e.g., see Chang, 2017; Lu et al., 2015). As faculty-led programs continue to be the most popular avenue college students use to travel abroad short-term (Spencer \& Tuma, 2002), we contest educators should concern 
Journal Committed to Social Change on Race and Ethnicity | 2018

themselves with the varied perspectives and experiences students have within their group and during their stay at the host country to foster dialogue and encourage development.

Intentional efforts for "guided, critical reflection" (Jackson, 2015, p. 98) and discussion need to be made at all stages of the study abroad process: during predeparture, during the trip abroad, and finally when returning home. Jackson (2015) noted that efforts at improving the study abroad experiences tend to target only one of these phases. However, trips abroad are most effective when they incorporate extensive preparatory study beforehand followed by reflection after returning home (Hulstrand, 2015; Spencer \& Tuma, 2002). The current review offers literature-based recommendations that faculty can adopt throughout the three interrelated steps in the study abroad process.

\section{Pre-departure}

Herbst (2011) provided a detailed account of the steps taken to build a faculty-led study abroad program in Istanbul, Turkey. In this account, Herbst (2011) discussed the promotional and recruitment efforts made which involved promotions during freshman and transfer orientation, general information sessions, information provided on websites, mass email and specified emails by major and minor, campus announcements, in-class announcements, and other avenues. The information provided through flyers and in-person sessions covered costs, accommodations, and other travel and academic logistics. Because parents and students raised concerns related to safety, Herbst (2011) made himself more available to students and their families. He had dinner with families, wrote to students personally, and was more available by phone 
and in-person. What is interesting to note in Herbst's (2011) account is that his availability seemed to be connected with familial concerns and was not an initial goal.

Remarkably, Lu et al. (2015) found that Black students placed a higher level of credit on their faculty member's personal interest in their intent to study abroad. The faculty member was the primary reason the students were engaged in studying abroad, and many expressed that they may not have studied abroad without his influence. They felt reassured in their faculty's personal interest in them, and they felt that their participation in the program was important to him.

A deeper understanding of how various demographics of students respond to study abroad recruitment allows faculty and study abroad offices to better recruit students and to recognize what competencies are needed to recruit diverse groups of participants. Faculty should use the pre-departure stage to get to know students as individuals, engage in dialogue, and learn what students may be fearful of while abroad. With this information, faculty can begin to consider how they will address certain scenarios with their group while abroad.

\section{While Abroad}

As research continues to explore how students increase levels of cultural competency while abroad (Earnest, Rosenbusch, Wallace-Williams, \& Keim, 2016; Smith et al., 2014), little is written about intragroup experiences. Chang's (2017) study exposed how disconnected Latina students and White students were in their study abroad program in Guatemala. Participants acknowledged the disconnect that manifested in everyday interactions, but these moment of cultural dissonance were not superficial. White students were disrespectful to Guatemalan residents, and many of 
Journal Committed to Social Change on Race and Ethnicity | 2018

them did not recognize the disrespectful behaviors, but the Latina students did. Some Latina participants even became angry with the White students because of their seeming disregard for the Guatemalan people. The interactions with the faculty member on this trip and participants were not discussed, but Chang's (2017) findings hint to the need for faculty to develop diversity competence to be able to recognize issues that emerge, engage in dialogue with a diverse group of students, to understand the different perspectives of diverse students, and to be able to successfully address intragroup issues.

\section{Returning Home}

As studies suggest an increase in cultural competency as a result of studying abroad, Lowe, Byron, and Mennicke (2014) found that Students of Color, when compared to their White counterparts, were more likely to report their study abroad experiences having a positive impact on their likelihood to interact with people who hold different racial identities. While studies often put an emphasis on diversity/cultural competency, the ways diversity/cultural competencies manifest vary in relation to race and ethnicity. Faculty need to have some sense of diversity competency to encourage such understandings. Supporting students as they reflect on their experiences and being able to validate their interpretations are ways to effectively achieve this goal.

\section{Recommendations for Practice}

As noted earlier, we recognize study abroad programs as a type of diversity education (Bierema, 2010) since students are expected to immerse themselves in a new culture and environment. Given this, we draw upon Bierema's (2010) work related to diversity education in relation to building competencies for study abroad programs. 
Bierema (2010) suggested that the faculty most qualified to teach diversity curricula recognize their positionality; have experience with marginalization; view diversity education as a developmental process; are knowledgeable of the subject; and, have the ability to facilitate diversity pedagogy. In relation to study abroad programs, we assert that understanding positionality, understanding diversity education and cultural immersion as a developmental process, and having the ability to facilitate diversity pedagogy are the most important components needed to build diversity competency and facilitate a study abroad program that is considerate of a diverse student population. Therefore, faculty could develop their understanding of topics such as diversity, marginalization, and the influence of structural oppressions to begin their diversity competence development.

Bierema (2010) suggested that educators can assist learners in evaluating their experiences and perspectives on diversity and how that affects their actions and thoughts. We agree and suggest that faculty also need to engage in intentional, critical, self-reflection of their experiences and how those experiences inform their understanding of the world, or, what is called their positionality. Reflecting on one's positionality is important because it is not static, and this is especially true when traveling abroad. There are shifts in privilege and oppression based on race, gender, nationality, etc. in different social environments and locations. Faculty must recognize their positionality in the context of the United States and within the context of the host country. This allows for more engaged dialogue and understanding of students' experiences. 
Learning and development does not occur overnight, and faculty should acknowledge their roles as instructor and learner during the experience (Mullens \& Cuper, 2012). As faculty navigate the new space of teaching abroad, self-reflection is vital to process personal customs and traditions in relation to the host country (Mullens \& Cuper, 2012). This time is also important to reflect on one's role as supervisor and leader of a diverse group of students. In addition, this is a time to consider the positionalities of each student and each student's interactions with the host country and their peers. This is also a time to consider how one will intentionally engage with the students to support an overall positive experience for all. Developing diversity competency is a process, and faculty are not exempt.

Faculty also need to be able to relate to learners who are coming from different perspectives (Bierema, 2010). This is especially true when involving diverse groups of study abroad participants. As previously discussed, students may interpret events during the trip differently based on their positionalities. Therefore, faculty must be equipped with the tools needed to address different concerns and problems students may have within the study abroad group of participants. This is why faculty must be knowledgeable of various pedagogies and theories related to diversity and cultural competency (Bierema, 2010).

Finally, faculty must display their competencies through pedagogy and action. Bierima's (2010) borrows Maher and Tetreault's (1994) four aspects of the feminist classroom as a framework to build diversity pedagogy. The four tenets are:

1) Mastery - to assist all learners involved in developing meaning about diverse issues and how these issues in their lives relate to a larger context by creating a community of learners. 
2) Voice - fashioning voice rather than finding one's voice by creating an engaging space that allows reflection. "Voice involves both the discovery and shaping of new knowledge with the influence of multiple perspectives" (Maher \& Tetreault, 1994. p. 325).

3) Authority - The intentional promotion of the student's "responsibility of learning and facilitating knowledge creation" (Maher \& Tetreault, 1994. p. 326) by rendering one's positional authority as the instructor.

4) Positionality - being mindful of one's positionality when attempting to make meaning of one's personal experiences or in understanding students' experiences (Maher \& Tetreault, 1994).

If institutions of higher education can commit to placing diversity and equity as

fundamental to their institutional cultures, it will positively influence the structure of study abroad programs and the trainings faculty must have to lead such programs. Even if institutions of higher education do not place emphases on building inclusive campus cultures, faculty still have agency and the ability to recognize their strengths and weaknesses when working with diverse groups in study abroad setting using diversity competence as the guide.

\section{Conclusion}

As studying abroad continues to become more popular for U.S. students, faculty who lead these programs need to be better prepared to work with diverse groups of students while abroad. Most research concerning diversity/cultural competency is related to how students are more likely to return home with a greater appreciation for diversity and international affairs, but limited research is focused on how faculty engage with students in relation to diversity/cultural competency. More studies should focus on building diversity competency with faculty who lead study abroad programs before they begin recruiting participants. In addition, research should also identify strategies for dealing with intragroup conflict while abroad. Not only has research suggested that 
students of marginalized backgrounds are more likely to feel alienated within their groups while abroad, but also research suggests that there are limited interventions taking place during the study abroad programs. While faculty may be prepared to travel and teach material related to the study abroad program, our critical review of research indicates that there is limited in-depth preparation for facilitating a diverse study abroad program, and this is a disservice to faculty and students.

Through our review of the literature, we found there are documented differences in intent, obstacles, and experiences concerning study abroad programs for college students. Many Students of Color interpreted their experiences abroad differently compared to their White counterparts. Some of these experiences proved to negatively impact students' experiences abroad because of their interactions with their White peers abroad. As study abroad participants continuingly become more diverse, faculty who lead such programs need to be prepared to address intragroup conflicts and differences that may arise. Anderson, Lorenz, and White (2016) argue that faculty can positively influence students' intercultural competence development through a competency framework, and we agree, but extend this argument suggesting the competency development must start with the faculty member. 


\section{References}

Anderson, P. H., Lawton, L., Rexeisen, R. J., \& Hubbard, A. C. (2006). Short-term study abroad and intercultural sensitivity: A pilot study. International Journal of Intercultural Relations, 30(4), 457-469.

Anderson, C. A., Lorenz, K., \& White, M. (2016). Instructor influence on student intercultural gains and learning during instructor-led, short-term study abroad. Frontiers: The Interdisciplinary Journal of Study Abroad, 28, 1-23.

Bierema, L. L. (2010). Diversity education: Competencies and strategies for educators. Advances in Developing Human Resources, 12(3), 312-331.

Chang, A. (2017). Call me a little critical if you will: Counterstories of Latinas studying abroad in Guatemala. Journal of Hispanic Higher Education, 16(1), 3-23.

Chun, E., \& Evans, A. (2016). Rethinking cultural competence in higher education: An ecological framework for student development. ASHE Higher Education Report, 42(4), 7-162.

Cox, T., \& Beale, R. L. (1997). Developing competency to manage diversity: Readings, cases \& activities (1st ed.). San Francisco, CA: Berrett-Koehler.

Donnelly-Smith, L. (2009, Fall). Global learning through short-term study abroad. Peer Review, 11(4). Retrieved from https://www.aacu.org/peerreview/2009/fall/donnelly-smith

Dwyer, M. M. (2004). More is better: The impact of study abroad program duration. Frontiers: The Interdisciplinary Journal of Study Abroad, 10, 151-164.

Earnest, D. R., Rosenbusch, K., Wallace-Williams, D., \& Keim, A. C. (2016). Study abroad in psychology: Increasing cultural competencies through experiential learning. Teaching of Psychology, 43(1), 75-79.

Fischer, K. (2009). Short study-abroad trips can have lasting effect, research suggests. The Chronicle of Higher Education. Retrieved from http://chronicle.com/daily/2009/02/12191n.htm

Frank, J. R., Snell, L. S., Cate, O. T., Holmboe, E. S., Carraccio, C., Swing, S. R., Harris, P., Harris, K. A. (2010). Competency-based medical education: Theory to practice. Medical Teacher, 32(8), 638-645.

Gaia, A. C. (2015). Short-term faculty-led study abroad programs enhance cultural exchange and self-awareness. The International Education Journal: Comparative Perspectives, 14(1), 21-31.

Herbst, M. T. (2011). Building a faculty-led study abroad program: From development to history pedagogy in Istanbul. The History Teacher, 44(2), 209-226.

Hovde, P. (2002). Opening doors: Alternative pedagogies for short-term programs abroad. In S. E. Spencer and L. Tuma (Eds.), Successful Short-Term Programs Abroad (pp. 1-7). Washington, DC: NAFSA. Retrieved from https://www.nafsa.org/uploadedFiles/guide_to_successful_shortterm.pdf? $\mathrm{n}=3985$

Hulstrand, J. (2015). Best practices for short-term, faculty-led programs abroad. International Educator, 24(3), 58-62.

Institute of International Education. (2017). "Detailed Duration of U.S. Study Abroad, 2005/6-2015/6." Open Doors Report on International Educational Exchange. Retrieved from http://www.iie.org/opendoors 
Jackson, J. (2015). Becoming interculturally competent: Theory to practice in international education. International Journal of Intercultural Relations, 48, 91107.

Lowe, M. R., Byron, R. A., \& Mennicke, S. (2014). The racialized impact of study abroad on US students' subsequent interracial interactions. Education Research International, 2014, 1-9. doi:10.1155/2014/232687

Lu, C., Reddick, R., Dean, D., \& Pecero, V. (2015). Coloring up study abroad: Exploring Black students' decision to study in China. Journal of Student Affairs Research and Practice, 52(4), 440-451.

Maher, F. A., \& Tetreault, M. K. T. (1994). The feminist classroom. New York, NY: BasicBooks.

Mapp, S. C. (2012). Effect of short-term study abroad programs on students' cultural adaptability. Journal of Social Work Education, 48(4), 727-737.

Mitchell, D., Jr., \& Maloff, A. (2016). Racial positionalities, professional development, and a master's study abroad experience in Jamaica for preparing student affairs professionals. College Student Affairs Journal, 34(2), 3-15.

Mohajeri Norris, E., \& Gillespie, J. (2008). How study abroad shapes global careers: Evidence from the united states. Journal of Studies in International Education, 13(3), 382-397.

Mullens, J. B., \& Cuper, P. H. (2012). Fostering global citizenship through faculty-led international programs. Charlotte, NC: Information Age Pub.

Rhodes, G., Biscarra, A., Loberg, L., \& Roller, K. (2012). Study abroad as a collaborative endeavor. About Campus, 16(6), 2-10.

Sachau, D., Brasher, N., \& Fee, S. (2010). Three models for short-term study abroad. Journal of Management Education, 34(5), 645-670.

Salisbury, M. H., Paulsen, M. B., \& Pascarella, E. T. (2011). Why do all the study abroad students look alike? Allying an integrated student choice model to explore differences in the factors that influence White and minority students' intent to study abroad. Research in Higher Education, 52(2), 123-150.

Shallenberger, D. (2015). Learning from our mistakes: International educators reflect. Frontiers: The Interdisciplinary Journal of Study Abroad, 26(1), 248-263.

Smith, M. D. M., Jennings, L., \& Lakhan, S. (2014). International education and service learning: Approaches toward cultural competency and social justice. Counseling Psychologist, 42(8), 1188-1214.

Spencer, S. E., \& Tuma, K. (2002). Introduction. In S. E. Spencer and L. Tuma (Eds.), Successful Short-Term Programs Abroad (pp. xv-xvii). Washington, DC: NAFSA. Retrieved from https://www.nafsa.org/uploadedFiles/guide_to_successful_shortterm.pdf?n=3985

Trilokekar, R. D., \& Kukar, P. (2011). Disorienting experiences during study abroad: Reflections of pre-service teacher candidates. Teaching and Teacher Education, 27(7), 1141-1150. 